\title{
RELAÇÕES DE PRODUÇÃO, TRABALHO, AMBIENTE E SAÚDE EM COMPLEXO AUTOMOTIVO MULTINACIONAL EM PERNAMBUCO
}

\author{
RELATIONSHIPS OF PRODUCTION, WORK, ENVIRONMENT AND HEALTH IN \\ A MULTINATIONAL AUTOMOTIVE COMPLEX IN PERNAMBUCO, BRAZIL
}

Isabelle Maria Mendes de Araujo ${ }^{1}$ iD)(0000-0001-9732-2003), Angelo Giuseppe Roncalli da Costa Oliveira $^{2}$ iD) (0000-0001-5311-697X)

${ }^{1}$ Instituto de Educação Superior da Paraíba, Departamento de Fisioterapia, João Pessoa, Paraíba, Brasil. <isabellesaudelivre@hotmail.com>

${ }^{2}$ Universidade Federal do Rio Grande do Norte, Centro de Ciências da Saúde, Departamento de Saúde Coletiva, Natal, Rio Grande do Norte, Brasil.

Resumo O estudo que originou este artigo, realizado entre 2015 e 2017, busca a compreensão de possíveis relações no âmbito produtivo, ambiental e sanitário na cidade de Goiana, Pernambuco, diante da chegada do empreendimento multinacional da Fiat Chrysler Automobiles. Objetivou-se construir uma matriz explicativa com base no framework força motriz-pressão-situaçãoexposição-efeito-ação com sistematização de indicadores para o monitoramento de mudanças no território que possam afetar a saúde da população local e o ambiente decorrentes da instalação do complexo automotivo. Para tal, foram propostos componentes descritivos para cada dimensão da matriz e realizada sistematização de dados secundários em diferentes bancos de dados. Houve apreensão de efeitos ao bem viver no contexto local resultantes da exposição territorial ao aumento da violência, precarização e agravos relacionados ao trabalho, contaminação ambiental e saneamento básico precário. São propostas ações para o enfrentamento de problemas complexos e sistêmicos identificados, as quais podem subsidiar estratégias para a vigilância em saúde ambiental e em saúde do trabalhador. Por meio do framework, podemos traçar processos de vulnerabilização no território local associando-os a forças estruturantes produtivas e a modificações na situação da reprodução social.

Palavras-chave vulnerabilidade; vigilância em saúde ambiental; saúde do trabalhador.
Abstract The study that originated the present article, which was conducted between 2015 and 2017, has the goal of understanding the possible relationships in the productive, environmental and sanitary contexts in the municipality of Goiana, in the state of Pernambuco, Brazil, with the arrival of the Fiat Chrysler Automobiles multinational enterprise. We aimed at developing an explanatory matrix based on the Driving force-Pressure-State-Exposure-Effect-Action framework, with the systematization of indicators for the monitoring of changes in the territory that could affect the health of the local population and the environment due to the establishment of the automotive complex. In order to do so, we proposed descriptive components for each dimension of the matrix, and we performed a systematization of secondary data in different databanks. We noticed effects on the wellbeing within the local context due to the territorial exposure to an increase in violence, precarization and injuries related to work, environmental contamination and precarious sanitation. In order to face the complex and systematic problems identified, we propose actions that can subsidize strategies for the vigilance in environmental health and in the health of the worker. Through the framework, we can describe processes of vulnerabilization in the local territories, associating them with productive structuring forces and changes in the social reproduction situation.

Keywords vulnerability; vigilance in environmental health; health of the worker. 


\section{Introdução}

No plano territorial, em relação aos usos, sentidos e disputas, os conflitos socioambientais emergem a partir das assimetrias instituídas entre os agentes de grandes empreendimentos, apoiados, em sua maioria, pelo Estado, e as comunidades ameaçadas e afetadas por esses projetos. Tais projetos são característicos de modelos de desenvolvimento predominantes nos países do sul global, baseados em uma forma de concentração do capital cujo cerne é a acumulação por espoliação, lógica perversa de expansão do capital marcada pela apropriação da natureza; expulsão violenta de populações camponesas, quilombolas e indígenas; superexploração da força de trabalho e supressão de formas alternativas tradicionais de produção e consumo; processos neocoloniais de dominação (Porto et al., 2015; Rigotto et al., 2018).

A chegada de grandes empreendimentos industriais costuma interferir nos espaços de vida de diferentes povos e comunidades tradicionais (Araújo e Oliveira, 2017), com modificação da paisagem, pressões sobre as formas de organização social da produção e do trabalho, reconfigurando o tempo e as relações sociais - com repercussões sobre a vida da população, a saúde, o acesso à terra, o trabalho digno, fortemente expressas no processo saúde e doença. Essa compreensão requer um olhar ampliado e análise da reprodução social singular e coletiva.

A Organização Mundial da Saúde (OMS) desenvolveu uma abordagem teórico-conceitual com o objetivo de mensurar e monitorar os possíveis agravos à saúde decorrentes das constantes e intensas mudanças sociais, econômicas e ambientais nos países (Gentry-Shields e Bartram, 2014). O modelo envolve a sistematização de diferentes dimensões: força motriz, pressão, situação, exposição e efeitos, incorporando a relação das exposições aos problemas ambientais e os possíveis efeitos, diretos ou indiretos, sobre a saúde dos humanos. Ressalta-se que o modelo força motriz-pressão-situação-exposição-efeito-ação (FPSEEA) para a construção de indicadores de saúde ambiental vem sendo proposto e utilizado na implantação da Vigilância em Saúde Ambiental no âmbito do Sistema Único de Saúde (SUS) nos últimos anos (Brasil, 2011).

O framework FPSEEA permite a sistematização de indicadores ambientais, sociais, econômicos e de saúde de forma integrada e sistêmica. Organizados em uma matriz, facilitam a análise das inter-relações de processos produtivos, das dinâmicas de trabalho, das interferências no ambiente e das repercussões sobre a saúde humana.

As pressões sobre o ambiente e a saúde têm relações mediadas ou moduladas com as forças motrizes mais amplas que representam a forma como uma sociedade se organiza econômica, política e culturalmente. Outro ponto importante é a relação entre as mudanças na situação/estado do ambiente, a 
exposição humana a essas alterações e os possíveis efeitos sobre a saúde, o que representa um avanço na construção de indicadores de saúde ambiental, pois permite incorporar não só as causas imediatas na compreensão dos problemas de saúde, mas também seus determinantes e condicionantes. Desse modo, pode-se propor ações para mitigá-los e, se possível, resolvê-los (Carneiro, 2006).

Nesse sentido, objetivou-se construir uma matriz explicativa com base no framework FPSEEA, com a sistematização de indicadores para o monitoramento de mudanças no território que possam afetar a saúde da população local e o ambiente decorrentes da instalação do complexo automotivo.

\section{Cenário do estudo}

O município de Goiana, localizado na zona da mata norte de Pernambuco, possui território de $501 \mathrm{~km}^{2}$ de extensão e uma população total de 79.249 habitantes (Instituto Brasileiro de Geografia e Estatística, 2017). Nesse território, observaram-se a instalação do complexo polo automotivo da Fiat Chrysler Automobiles (FCA) e as repercussões desse processo no contexto local, de 2015 a 2017, para construir uma matriz preditiva de vulnerabilidades com referência ao empreendimento industrial.

O município de Goiana historicamente teve sua economia fundada no predomínio da monocultura da cana-de-açúcar, com graves problemas daí decorrentes. Atualmente, integra uma região de desenvolvimento industrial do estado com muitos empreendimentos, a exemplo da indústria de hemoderivados e a automobilística (Condepe/Fidem, 2010). No entorno do empreendimento automotivo da Fiat há a reserva extrativista Acaú-Goiana, área sob proteção do órgão ambiental Instituto Chico Mendes de Conservação da Biodiversidade (ICMBio), composta por diversas comunidades extrativistas que vêm sendo, de diferentes formas, impactadas pelo complexo automotivo.

Para a construção da matriz FPSEEA, tivemos como questão norteadora: “como um empreendimento global, o complexo automotivo FCA/Jeep, alinhado à reestruturação produtiva do capital industrial, desencadeia processos de vulnerabilização (sanitária, social, ecológica e econômica) ao instalar-se em um território local, no caso, no município de Goiana, Pernambuco?" Desse modo, para evidenciarmos os impactos/efeitos à saúde da população local e ao ambiente, foram propostos componentes descritivos para cada dimensão da matriz e sistematizada uma série de indicadores em diferentes bancos de dados do país, referentes ao período de 2010 a 2017, a fim de compor tais indicadores do framework. Os dados foram trabalhados no Excel 2010. Houve também pesquisa documental, de processos jurídicos, notícias jornalísticas estaduais de Pernambuco, compondo parte dos dados levantados de acordo com a proposta da triangulação de metodologia da pesquisa (Minayo, 2010). 
Para Liu e colaboradores (2012), as vantagens do FPSEEA são: reconhecer as ligações entre a exposição e os efeitos na saúde; permitir a incorporação de dados de entrada na cadeia de causalidade, ligando-a a níveis de ações que podem ser tomadas para reduzir os impactos à saúde ambiental; estender o conceito de força motriz a fatores mais remotos e contextuais, tais como sociais e desenvolvimento econômico. Além de flexível, esse modelo pode ser adaptado e modificado de acordo com as circunstâncias.

Contudo, uma das limitações do modelo é que a dimensão cultural e histórica não transparece nos níveis organizativos dos indicadores, de modo que o pesquisador deve atentar para não reduzir suas análises a uma perspectiva linear de causalidade, observando os processos complexos da realidade em articulação com as dimensões propostas.

Dentre as diferentes abordagens com o uso do modelo de indicadores em saúde ambiental, o FPSEEA já foi adotado para monitorar impactos sobre a saúde decorrentes das mudanças climáticas na Europa; desenvolver indicadores de saúde ambiental para avaliação e monitoramento da vulnerabilidade da saúde humana; e medir a eficácia de adaptação e mitigação das mudanças climáticas (Hambling et al., 2011).

Para o estudo aqui apresentado, o Quadro 1 permite a observação das dimensões do modelo FPSEEA, os componentes descritivos, os indicadores relacionados e as respectivas base de dados/fontes.

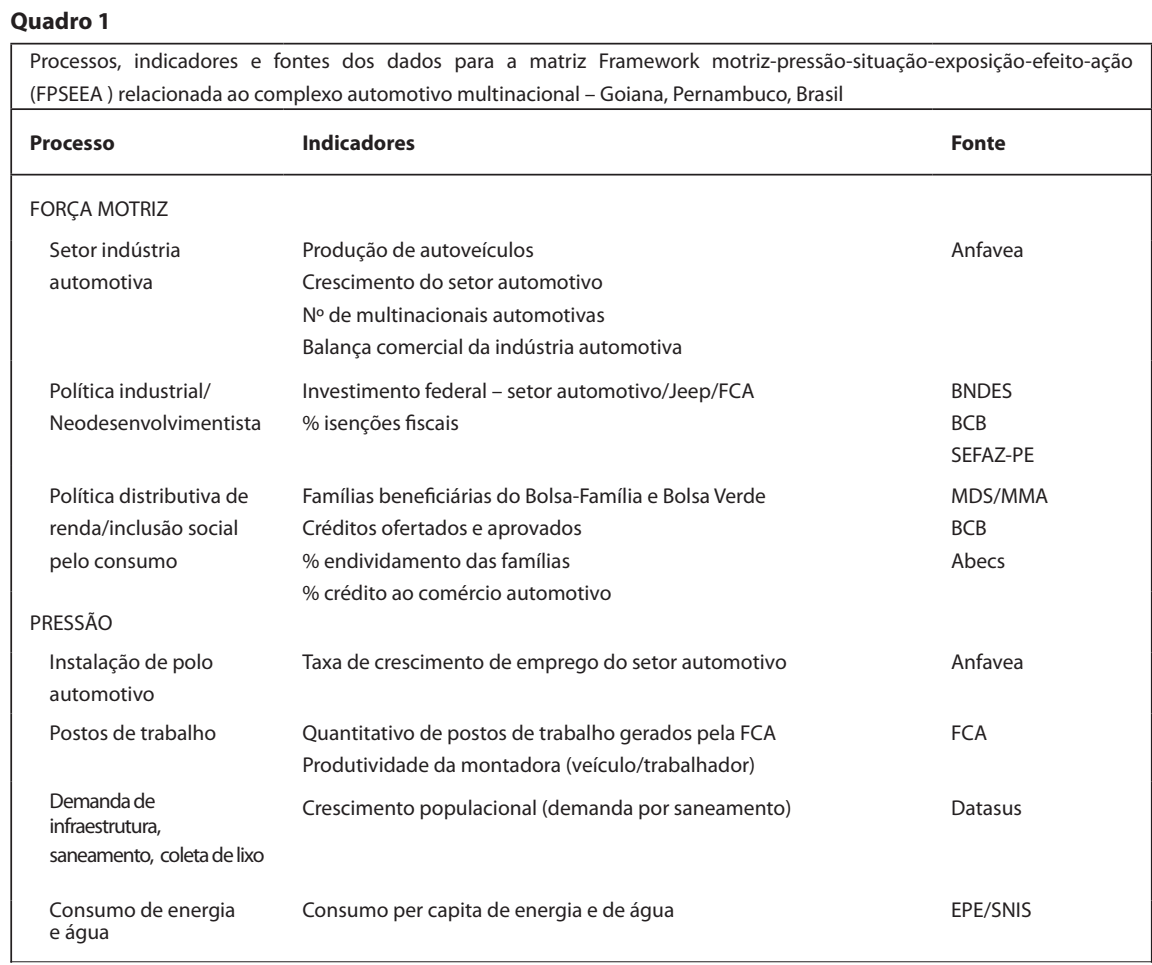


Continuação do Quadro 1

\begin{tabular}{|c|c|c|}
\hline \multicolumn{3}{|c|}{$\begin{array}{l}\text { Processos, indicadores e fontes dos dados para a matriz FPSEEA relacionada ao complexo automotivo } \\
\text { multinacional - Goiana, Pernambuco, Brasil }\end{array}$} \\
\hline Consumo de bens & $\begin{array}{l}\text { Percentual de domicílios particulares permanentes que utilizam a } \\
\text { internet } \\
\text { Percentual de pessoas de } 10 \text { anos ou mais de idade que possuíam } \\
\text { telefone móvel celular } \\
\text { Número de estabelecimentos por setor }\end{array}$ & $\mathrm{BDE} / \mathrm{PE}$ \\
\hline \multicolumn{3}{|l|}{ SITUAÇÃO } \\
\hline Motorização/frota & Taxa de motorização/frota & IBGE/DENATRAN \\
\hline $\begin{array}{l}\text { Emissões atmosféricas } \\
\text { por veículos automotores }\end{array}$ & Quantitativo de emissões de poluentes por automóveis/ano & MMA \\
\hline $\begin{array}{l}\text { Saneamento ambiental } \\
\text { Resíduos sólidos }\end{array}$ & Cobertura da coleta de resíduos sólidos e destinação de lixo & IBGE/SNSA \\
\hline $\begin{array}{l}\text { Sistema de } \\
\text { abastecimento de água }\end{array}$ & Cobertura domiciliar de abastecimento/situação de água potável & SNIS/ANA \\
\hline $\begin{array}{l}\text { Contaminação das } \\
\text { águas/solo }\end{array}$ & Qualidade da água dos rios & SNIS/ ANA \\
\hline \multirow[t]{4}{*}{ Precarização do trabalho } & $\begin{array}{l}\text { Número de empregos formais por setor } \\
\text { Rotatividade de emprego formal }\end{array}$ & $\mathrm{BDE} / \mathrm{PE}$ \\
\hline & $\begin{array}{l}\text { Percentual de ocupados por escolaridade } \\
\text { Percentual de ocupados por rendimento }\end{array}$ & Atlas Brasil \\
\hline & $\begin{array}{l}\text { Terceirizados da montadora } \\
\text { Taxa de sindicalização }\end{array}$ & Sindmetal-PE \\
\hline & $\begin{array}{l}\text { Indice de Desenvolvimento Humano Municipal } \\
\text { Índice de Gini }\end{array}$ & IBGE \\
\hline EXPOSIÇÃO & & \\
\hline $\begin{array}{l}\text { Saneamento ambiental } \\
\text { inadequado }\end{array}$ & Proporção de pessoas com saneamento inadequado & IBGE/Datasus \\
\hline Água contaminada & Proporção de pessoas sem acesso a água tratada & ANA \\
\hline Poluição ambiental & Presença de poluentes nos rios & CPRH/ANA \\
\hline Acidentes ocupacionais & $\begin{array}{l}\% \text { de afastamento do trabalho por doença ou acidente ocupacional } \\
\text { Número de acidentes/agravos relacionados ao trabalho }\end{array}$ & $\begin{array}{l}\text { Cerest } \\
\text { Painel Renast }\end{array}$ \\
\hline $\begin{array}{l}\text { Violência urbana } \\
\text { EFEITOS }\end{array}$ & Taxa de criminalidade violenta letal e intencional & $\mathrm{BDE} / \mathrm{PE}$ \\
\hline $\begin{array}{l}\text { Lesões, mortalidade, } \\
\text { invalidez ocupacionais }\end{array}$ & $\begin{array}{l}\% \text { acidentes, doenças e óbitos relacionados ao trabalho } \\
\text { Agravos relacionados ao trabalho notificados }\end{array}$ & $\begin{array}{l}\text { DataPrev/Painel } \\
\text { Renast } \\
\text { Sinan/Painel Renast }\end{array}$ \\
\hline $\begin{array}{l}\text { Doenças por saneamento } \\
\text { ambiental inadequado }\end{array}$ & Internações relacionadas ao saneamento ambiental inadequado & Datasus \\
\hline Desequilíbrio ambiental & $\begin{array}{l}\text { Quantitativo de intoxicações por agrotóxicos } \\
\text { Mortes de peixes, assoreamento de rios }\end{array}$ & $\begin{array}{l}\text { DataSUS/Sinitox } \\
\text { ICMBio/CPRH }\end{array}$ \\
\hline Vítimas de violência & Morbimortalidade por causas externas/agressões & $\begin{array}{l}\text { Datasus/Mapa da } \\
\text { violência }\end{array}$ \\
\hline
\end{tabular}

Fonte: Elaboração dos autores, 2018.

ABECS: Associação Brasileira das Empresas de Cartões de Crédito e Serviços. ANA: Agência Nacional de Águas. ANFAVEA: Associação Nacional dos. Fabricantes de Veículos Automotores. BCB: Banco Central do Brasil. BDE-PE: Banco de Dados do Estado de Pernambuco. BNDES: Banco Nacional de Desenvolvimento Econômico e Social. CEREST: Centro de Referência em Saúde do Trabalhador. CPRH: Agência Estadual de Meio Ambiente de Pernambuco. DataPrev: Empresa de Tecnologia e Informações da Previdência Social. Datasus: Dados do Sistema Único de Saúde. EPE: Empresa de Pesquisa Energética. SNIS: Sistema Nacional de Informações sobre Saneamento. FCA: Fiat Chrysler Automobiles. IBGE: Instituto Brasileiro de Geografia e Estatística. DENATRAN: Departamento Nacional de Trânsito. SNSA: Sistema Nacional de Saneamento Ambiental. ICMBio: Instituto Chico Mendes de Conservação da Biodiversidade. MDS: Ministério do Desenvolvimento Social. MMA: Ministério do Meio Ambiente. RENAST: Rede Nacional de Atenção Integral à Saúde do Trabalhador. SEFAZ-PE: Secretaria da Fazenda do Estado de Pernambuco. SINAN: Sistema de Informação de Agravos de Notificação. Sindmetal-PE: Sindicato dos metalúrgicos de Pernambuco. SINITOX: Sistema Nacional de Informações Tóxico-Farmacológicas. 
O projeto de pesquisa foi aprovado pelo Comitê de Ética em Pesquisa da Universidade Federal do Rio Grande do Norte, parecer favorável n. $1.102 .096 / 2015$.

\section{Determinação socioambiental da saúde: perspectivas do framework FPSEEA}

A descrição dos componentes que integraram o framework FPSEEA foi fruto de revisão crítica da literatura articulada à discussão sobre a reestruturação produtiva do capital, propriamente do setor automotivo; ao modelo econômico do Brasil em suas políticas de base industrial; e à política de distribuição de renda, as quais teceram o tripé do quadro das forças motrizes relacionadas à instalação de um empreendimento industrial global, a FCA, e às pressões deste sobre o território local - no caso, no território de Goiana.

Com base na representação esquemática das dimensões da matriz explicativa FPSEEA (Figura 1), podemos dialogar com a concepção teórico-conceitual da determinação social do processo saúde-doença relacionada à construção de matrizes de processos críticos do adoecimento propostas por Breilh (2003). Essa concepção tem como finalidade aprofundar a perspectiva de vigilância e monitoramento das determinações sociais da saúde (Breilh, 2015) e traçar a relação das dimensões da lógica estrutural produtiva, de consumo, do Estado, das condições ecológicas, bem como os modos e estilos de vida singular nos sistemas sociais. 
Figura 1

Framework motriz-pressão-situação-exposição-efeito-ação (FPSEEA): matriz explicativa relacionada à instalação do complexo automotivo - Goiana, Pernambuco, Brasil

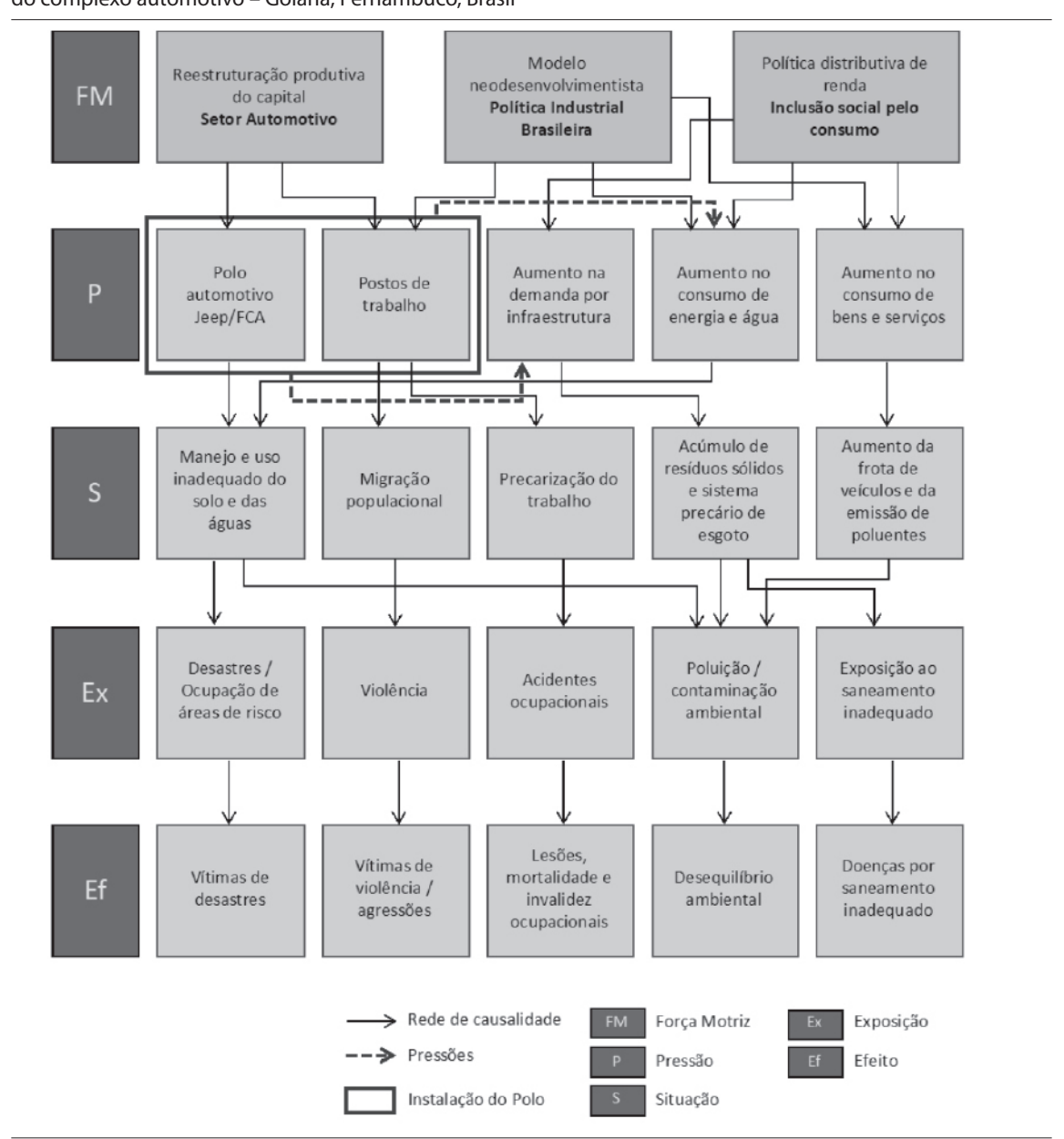

Fonte: Elaboração dos autores, 2018.

FCA: Fiat Chrysler Automobiles

Segundo Porto e colaboradores (2014), os problemas de saúde e sua determinação socioambiental são complexos e multidimensionais, pois envolvem simultaneamente questões sociopolíticas, econômicas, culturais e biológicas, dentre outras, o que implica uma pluralidade de perspectivas teóricas e metodológicas. Desse modo, um enfoque socioambiental para a compreensão dos problemas complexos de saúde se faz necessário, assim como para a análise das modificações no território de Goiana (PE), como Tambellini (2012) sentencia: o ambiente socialmente configurado é a força motriz das condições de vida e saúde/doença das populações. 
Nessa perspectiva, os processos de vulnerabilização também emergem, resultantes de arranjos de estruturas socioeconômicas que produzem, simultaneamente, condições de vida precárias e ambientes deteriorados e expropriados devido à atuação de cadeias produtivas capitalistas (Araújo e Oliveira, 2017).

Ao considerar cada dimensão da matriz FPSEEA, discutimos seus componentes propostos na pesquisa associando-os a indicadores que explicitem os níveis de complexidade relacionados à determinação socioambiental da saúde.

\section{Força motriz}

O setor automotivo vinculado à reestruturação produtiva do capital compõe uma das forças motrizes da matriz explicativa, macrocomponente determinante no desencadeamento de processos de vulnerabilização (Porto, 2011) que potencialmente afetam a saúde humana. De acordo com Franco (2009), a indústria automobilística, em escala global e nacional, é marcada pela busca de espaços periféricos, configurando a nova geografia do setor. Ela é associada ao desenvolvimento tecnológico e às mudanças nos padrões de gestão da produção e do trabalho.

De modo a enfrentar os mercados saturados e a intensa disputa das empresas multinacionais do ramo automotivo, baseada na produtividade de escalas crescentes, as novas estratégias do sistema produtivo passam à redução permanente dos custos com volume constante, inovação e flexibilidade, produção enxuta (sistema just in time), todos mecanismos da automação flexível. No campo do trabalho, há redução significativa dos empregos na linha de montagem e intensificação do trabalho em escala sem precedentes (multifuncionalização) (Franco, 2009).

No ranking mundial, o ramo automotivo brasileiro é o décimo produtor e o sétimo de mercado interno. Em 2015, gerou R \$39,7 bilhões de tributos Imposto sobre Produtos Industrializados (IPI), Programa de Integração Social/ Contribuição para Financiamento da Seguridade Social (PIS/Cofins), Imposto sobre Operações Relativas à Circulação de Mercadorias e sobre Prestações de Serviços de Transporte Interestadual e Intermunicipal e de Comunicação (ICMS), Imposto sobre a Propriedade de Veículos Automotores (IPVA) -, com capacidade instalada de produção de 5,05 milhões de autoveículos, geração de mais de 1,3 milhão de empregos e participação no Produto Interno Bruto (PIB) brasileiro em 4\%, e na indústria de transformação em 22\% (Cardoso et al., 2015).

Outra força motriz em evidência é a política industrial do país, sob o jugo neodesenvolvimentista na década de 2000 a 2010, a qual, além de visar ao crescimento econômico (PIB), atentou para o fomento de indústrias que exercessem efeitos multiplicadores sobre vários outros setores da economia, com elementos geradores de emprego e renda. 
Como forma de tentar aumentar a competitividade do setor industrial, o governo Lula propôs em 2004 a Política Industrial, Tecnológica e de Comércio Exterior (PITCE), que lançou as bases para a Política de Desenvolvimento Produtivo (PDP), em maio de 2008, a qual teve como objetivo propiciar o crescimento econômico do país, impulsionado pelo desenvolvimento industrial, a fim de obter resultados na geração de empregos e aumento da competitividade. Logo após a sua implantação, a economia brasileira foi afetada pela crise econômica mundial; mesmo assim, o governo acelerou a implementação das medidas da PDP (Coronel e Azevedo, 2014). Destaca-se que um dos setores-alvo da política foi o complexo nacional automotivo, com o objetivo de fortalecimento da sua competitividade.

Quanto aos incentivos fiscais federais, o setor automotivo é o maior consumidor de benefícios fiscais no país, absorvendo 53,5\% de todos os incentivos concedidos. Em 2012, por intermédio da lei n. 12.715, o governo federal criou o Programa de Incentivo à Inovação Tecnológica e Adensamento da Cadeia Produtiva de Veículos Automotores (Inovar-Auto), com o objetivo de criar condições para o aumento de competitividade no setor automotivo, produzir veículos mais econômicos e seguros, investir na cadeia de fornecedores, em engenharia, tecnologia industrial básica, pesquisa e desenvolvimento e capacitação de fornecedores. O programa possibilitou o estímulo à concorrência e a busca de ganhos sistêmicos de eficiência e aumento de produtividade da cadeia automotiva, das etapas de fabricação até a rede de serviços tecnológicos e de comercialização (Alves, 2014).

Além dessas medidas, outro pilar das forças motrizes pesquisado foi a política de distribuição de renda e a dimensão da inclusão social pelo consumo. Evidenciamos o papel das políticas distributivas de renda, por transferência pública (Bolsa Família, Bolsa Verde) ou salarial (elevação do salário mínimo real), juntamente com a ampliação do acesso ao microcrédito das famílias na década de 2000, as quais alavancaram o padrão de consumo do país, numa perspectiva de inclusão pelo consumo, que configura cenário de forte pressão sobre o ambiente/natureza, a vida e a saúde das pessoas.

De acordo com Pochmann (2013), nos governos Lula e Dilma o salário mínimo registrou aumento de quase $54 \%$ em termos reais, com queda sensível no desemprego e na informalidade da mão de obra ocupada. Além disso, os programas de transferência de renda no Brasil tiveram crescimento exponencial, com forte impacto na redução da pobreza - o Programa Bolsa Família principalmente, para garantir uma renda mínima à população pobre, alcançando famílias cujos membros adultos estão em idade economicamente ativa para o mercado de trabalho. Nesse ciclo até 2015, quase um quinto da população brasileira, na composição familiar, era beneficiário do Bolsa Família.

Em outra vertente, no sentido de incrementar o mercado interno de consumo, houve consistente política de concessão de microcréditos. Segundo Alves 
(2014), de 2003 a 2013 a oferta de crédito cresceu cerca de 140\% no país. Para o autor, a ideia de cidadania reduziu-se à garantia de acesso ao mercado de consumo de massa, proliferando a inclusão social pelo consumo como meio de afirmação da identidade social.

A Figura 2 demonstra o crescimento das famílias beneficiárias de 2010 a 2017 no Brasil e no município de Goiana (PE). De 2013 a 2015, cerca de 50\% da população de Goiana era beneficiária do Programa Bolsa Família, o que destaca o importante número de famílias de baixa renda no município.

\section{Figura 2}

Número de famílias beneficiárias do Programa Bolsa Família, Brasil e Goiana (PE), entre 2010 e 2017

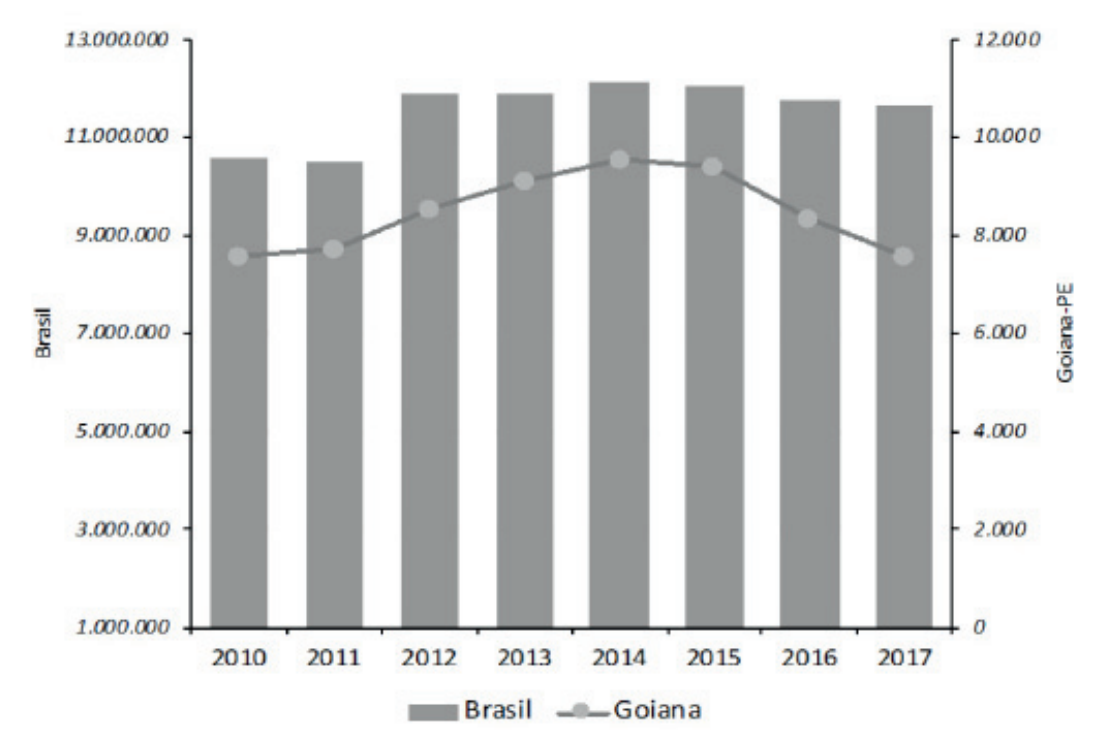

Fonte: Ministério do Desenvolvimento Social, Brasil (disponível em: <https://aplicacoes.mds.gov.br>; acesso em: 15 mar. 2018).

\section{Pressão}

Com base nas forças motrizes, são geradas diferentes 'pressões' sobre o ambiente/natureza do território. Essas pressões se expressam como consequência dos processos produtivos e da ocupação humana. De modo geral, são geradas por diversos setores da atividade econômica, como a mineração, a produção de energia, os serviços industriais, o transporte, o turismo, a agricultura. Em cada caso, as pressões surgem em todos os estágios da cadeia de produção, desde a extração dos recursos naturais, seu processamento e distribuição, até o consumidor final e os resíduos e efluentes produzidos (Brasil, 2011). Como exemplos das pressões importantes que alteram negativamente a situação do ambiente e 
podem acarretar efeitos adversos sobre a saúde, estão a ausência de tratamento de esgoto, o aumento de consumo de energia (combustíveis fósseis e hidrelétricas) e a crescente emissão de gases poluentes por veículos automotores.

Diante das forças motrizes apresentadas, observa-se que elas geram diferentes pressões sobre o território Goiana/Pernambuco. Na busca de espaços periféricos para a expansão da indústria automotiva internacional, Goiana torna-se atrativa e vantajosa, no cenário da reestruturação produtiva e da guerra fiscal, a exemplo da doação do terreno pelo estado de Pernambuco para a instalação da multinacional FCA no município, com menores salários para os trabalhadores, comparando-se com os da Fiat de Betim, Minas Gerais (Ladosky, 2015).

Com a instalação e operação da FCA, são evidenciadas outras pressões sobre o território: aumento da demanda por infraestrutura como saneamento, consumo de energia e água, consumo de bens, além da demanda pela geração de postos de trabalho.

Em Goiana, o percentual de admissão no setor da indústria de transformação, no qual o setor automotivo se encontra, vem crescendo em relação ao total de admissões no emprego formal, com novos postos de trabalho. Em 2013, as admissões foram de $43 \%$ do total de mais de 6 mil empregos gerados; em 2014,63,4\% de mais de 9 mil empregos; e em 2015, 76,2\% de mais de 10 mil empregos (Condepe/Fidem, 2017).

Segundo o Sistema Nacional de Informações sobre Saneamento (SNIS, 2017), o consumo médio per capita de água de Goiana saiu de 108 (1/hab./ dia) em 2011 para 139 (l/hab./dia) em 2015; e o consumo médio per capita de energia foi de 1.105 (Kwh/hab.) em 2011 para 5.196 (Kwh/hab.) em 2015 (Figura 3). Em relação ao setor industrial, houve um crescimento de $378 \%$ de consumo de energia elétrica (Mwh) de 2014 para 2015, ano do início da operação da montadora da Fiat-Goiana (BDE/PE, 2017). 
Figura 3

Consumo de energia elétrica (Mwh), Goiana , Pernambuco, por ano (2009/2016)

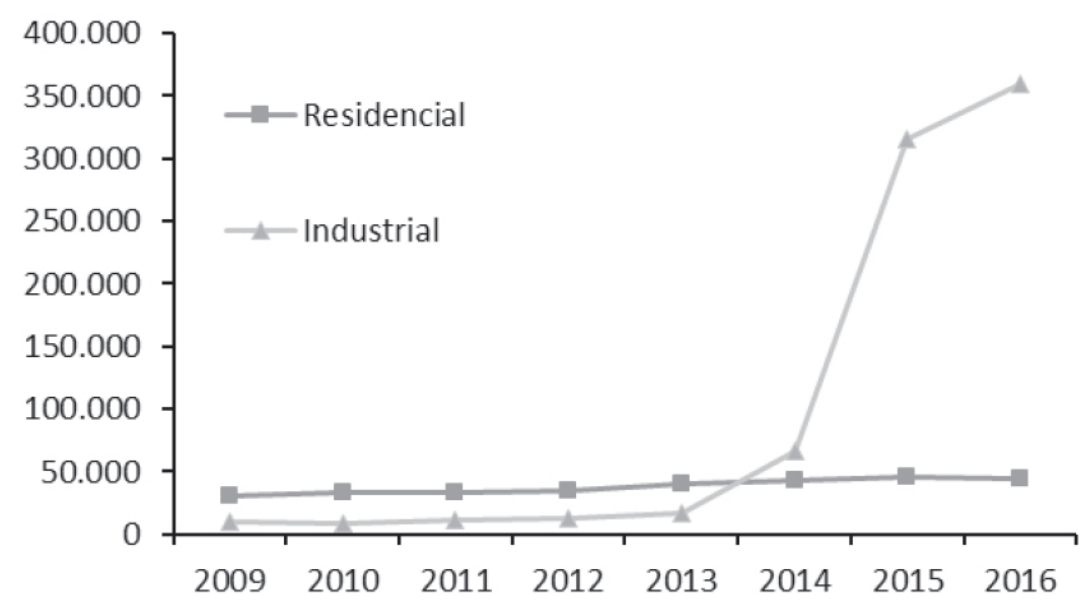

Fonte: Banco de dados do Estado de Pernambuco, 2017

Quanto à demanda por infraestrutura na cidade, a população cresceu $5 \%$ de 2010 (75.466 hab.) para 2015 (78.688 hab.), com permanência de precário esgotamento sanitário no município (23\% de domicílios ligados à rede geral de esgoto em 2010 e 34\% em 2015) (Brasil, 2017).

Já a pressão sobre o consumo de bens pode ser avaliada também por meio da emergência de novos estabelecimentos no território. Segundo a base de dados de Pernambuco (Condepe/Fidem, 2017), de 2010 a 2015 houve crescimento dos estabelecimentos por setor: construção civil, 108\%; indústria de transformação, 49\%; serviços, 36\%; e comércio, 4\%. Entretanto, desde 2016, um ano após a inauguração do complexo automotivo, houve fechamento/diminuição de estabelecimentos, especialmente do setor de serviços e comércio, ou seja, não aconteceram a fixação de empregos e a permanência do sugerido desdobramento positivo na cadeia produtiva de trabalho.

\section{Situação}

As pressões podem contribuir para aumentar a frequência ou a magnitude de determinadas situações ambientais que resultam em efeitos negativos sobre a saúde. A situação do ambiente estudado vem sendo modificada devido às diferentes pressões relativas à chegada da FCA/Jeep (pressão) e às crescentes demandas sobre o território. Desse modo, o ambiente é afetado pelo aumento da motorização/frota de veículos e pelas emissões atmosféricas por veículos automotores; pelo sistema de esgotamento sanitário precário; pelo uso e ocupação inadequada do solo pelos empreendimentos e migração populacional; pela contaminação das águas que abastecem a cidade; além da 
precarização do trabalho que potencialmente gera efeitos nocivos à saúde dos trabalhadores.

Houve um crescimento linear, nos últimos anos, da frota de veículos e da motorização. A frota passou de 16 mil veículos, em 2010, para 25 mil veículos, em 2014; e a taxa de motorização (número de automóveis/população x 100), de 24\%, em 2010, para 30\%, em 2014 (Condepe/Fidem, 2017).

Quanto à poluição ambiental, devido às mudanças na situação do território, a Agência Estadual de Meio Ambiente de Pernambuco (CPRH), que realiza o monitoramento da qualidade da água da Bacia Hidrográfica do Rio Goiana, encontrou significativa presença de poluentes nos rios que compõem essa bacia.

Segundo a CPRH (2017), a qualidade das águas dos rios da Bacia do Rio Goiana varia de poluída a muito poluída, com índice do estado trófico (IET) indicando produtividade de baixa a intermediária (alta ação antrópica), com possíveis implicações sobre a qualidade da água. Estudos (Araújo et al., 2016) apontam que, no processo industrial dos automóveis, são produzidos gases de efeito estufa, resíduos (sucata metálica, óleos e tintas, resíduos perigosos, resíduos inertes) e efluentes principalmente na fase de pintura. Ocorre poluição do ar a partir da névoa (etapa de aspersão) e evaporação dos banhos: $\mathrm{OH}-$, solventes e compostos orgânicos voláteis (COV), odor desagradável; rejeitos de água com produtos muito alcalinos, chumbo (concentração elevada); poluição dos solos e das águas devido à ruptura de canalização, de estocagem, acidentes; rejeitos industriais especiais por óleos, lodo no fundo dos tanques (metais: ferro, zinco e alumínio), ácido nítrico, dentre outros, todos prejudiciais à saúde.

Na questão dos novos postos de trabalho, há grande repercussão no campo trabalhista e educacional na perspectiva da inserção, flexibilização e precarização do trabalho. No período de 2013 a 2015, os dados sobre a rotatividade em emprego formal (Banco de dados do estado de Pernambuco, 2017) na cidade de Goiana demonstram que o setor que mais admitiu foi o de indústria de transformação (17.848 empregos formais), seguido do setor de serviços (3.834) e da construção civil (2.770). Todavia, tais setores foram os que mais realizaram demissões: 13.814 desligamentos de emprego formal na indústria de transformação, 3.675 em serviços, 2.257 na construção civil, o que evidencia forte rotatividade de emprego e a não ampliação efetiva de postos de trabalho.

\section{Exposição}

As mudanças na situação ambiental proporcionam diferentes exposições às condições de saúde da população local e à natureza, ou seja, geram processos de vulnerabilização socioambientais. A vulnerabilização a que a população está exposta refere-se, no caso, aos domicílios com saneamento ambiental inadequado (esgotamento sanitário, abastecimento de água, coleta e destinação de 
resíduos sólidos precários), à poluição dos rios, do solo e do ar (com presença de poluentes industriais), aos acidentes e agravos ocupacionais decorrentes do novo modelo produtivo do ramo automotivo. Devido à construção da montadora no entorno da reserva extrativista ambiental, há risco de impactos negativos sobre as nascentes dos rios e sobre o bioma local.

Quanto ao saneamento ambiental inadequado, em relação ao percentual de moradores do município de Goiana verificou-se que, em 2015, 67\% da população estava em domicílios com esgotamento sanitário inadequado; $42 \%$ com abastecimento inadequado de água; e 7\% sem coleta de lixo adequada. Em 2010, 78\% estavam em domicílios com esgotamento sanitário inadequado; $35 \%$ com abastecimento inadequado de água; e $16 \%$ sem coleta de lixo adequada (Brasil, 2017). O aumento populacional, portanto, não correspondeu ao melhoramento da rede de abastecimento de água e esgoto.

São dados preocupantes em relação à exposição da população ao saneamento ambiental inadequado, principalmente quanto ao acesso à água potável e aos serviços de esgotamento sanitário, demonstrando a lacuna que o município tem no eixo de investimento em infraestrutura básica, fator que expõe grande parte dos moradores a vetores e doenças relacionados à precariedade do saneamento.

Destaca-se que, em 2015, o ICMBio autuou a FCA por causar dano indireto à Resex Acaú Goiana, devido à erosão causada no córrego Japumim, tributário do Rio Tracunhaém, no interior da unidade de conservação - com multa diária de $\mathrm{R} \$ 3$ mil e obrigação da empresa em formalizar Termo de Compromisso e Plano de Recuperação de Área Degradada. Ao se considerar o princípio de precaução, que tutela o ambiente diante de danos ainda imensuráveis, constatou-se que a estrutura dissipadora de águas pluviais (projeto de drenagem do sistema viário que circunda a indústria), construída com o fito de reduzir a energia e o impacto da queda das águas, encontrava-se comprometida, de modo que o fluxo de água da chuva passou a ser contínuo e, por força da ausência de controle da vazão, teria desencadeado um processo erosivo (voçoroca) e contribuído, segundo a fiscalização ambiental do ICMBio, para a ocorrência de 'impactos negativos invisíveis' ao estuário da Resex Acaú-Goiana. Assim, poderia causar a mortandade de peixes e crustáceos; comprometer a economia dos pescadores da região; alterar a qualidade hídrica; causar dano à unidade de conservação; ou alterar o ciclo de vida dos animais (Tribunal Regional Federal da $5^{\text {a }}$ Região, 2015).

Entretanto, a empresa FCA recorreu à Justiça, alegando que esse projeto é de responsabilidade da Secretaria de Desenvolvimento de Pernambuco. Assim, nos autos jurídicos, o juiz dá voto em benefício da empresa (retira a multa e determina a retirada dos cadastros restritivos do ICMBio): “Carece de comprovação contundente e robusta a responsabilidade imputada à empresa 
agravante no que atine à prática de atos que culminariam com os supostos danos ambientais" (Tribunal Regional Federal da 5ª Região, 2015).

\section{Efeitos}

Por fim, evidenciam-se, diante de tal matriz explicativa, possíveis efeitos sobre a saúde ambiental e da população local, com processos de adoecimento ancorados na determinação socioambiental da saúde (Freitas et al., 2018). Em uma concepção ampliada de saúde, os efeitos não se restringem ao conjunto de doenças e óbitos que possam ser mensuráveis; envolvem também a compreensão de outros efeitos adversos sobre o bem-estar da população. Assim, os efeitos negativos à saúde da população de Goiana, determinados pelas questões socioambientais do território, referem-se às doenças por saneamento ambiental inadequado; às lesões, mortalidade e invalidez decorrentes do processo de trabalho na indústria automotiva; ao desequilíbrio ambiental (intoxicação humana, assoreamento de rios, mortandade de peixes); às vítimas de violência.

Em relação à morbidade hospitalar no município de Goiana, no período entre 2010 e 2016, os quatro grupos de morbidades prevalentes foram, primeiramente, as lesões por envenenamento e outras causas externas, seguidas das doenças do aparelho respiratório, doenças infecciosas e parasitárias e doenças do aparelho circulatório. Destaca-se que, em 2015, houve expressivo pico de casos de internações por lesões por envenenamento e algumas outras causas externas (558 casos), crescimento de $60 \%$ da prevalência dessa morbidade em relação a 2010 (Brasil, 2017). O estudo de Alochio (2011) aponta que cidades modificadas pela atuação de complexos industriais, no modelo da globalização, provocam mudanças no perfil de morbimortalidade da população local, como o aumento dos casos de internação hospitalar por causas externas.

De acordo com o levantamento da pesquisa, sugere-se que o perfil epidemiológico da população de Goiana esteja relacionado aos acometimentos derivados dos novos processos de trabalho industrial - além do histórico trabalho no campo e nas águas, com a pesca artesanal -, ao saneamento ambiental, à infraestrutura municipal e ao aumento da violência.

Outro grupo de efeito constituinte da nossa matriz explicativa refere-se ao trabalho. Segundo o Painel da Rede Nacional de Atenção Integral à Saúde do Trabalhador (Renast, 2017), observa-se o crescimento dos agravos relacionados ao trabalho (acidentes típicos) em Goiana de 2010 a 2015, com registro, em 2014, de 532 agravos totais. Na série histórica dos agravos por notificação, evidencia-se importante aumento de acidentes do trabalho em 2013, fase de instalação da montadora Fiat, quando se triplicam os casos, em especial, de acidentes de trabalho grave. Nesse cenário, temos $11,41 \%$ das notificações relacionadas ao sexo feminino e $88,59 \%$ ao masculino. 
De acordo com o Centro de Referência em Saúde do Trabalhador (Cerest) de Goiana (Renast, 2017), predominam as notificações de acidentes de trabalho relacionadas aos trabalhadores de produção de bens e serviços industriais, $45 \%$ do total de 190 registros em 2013, o que sinaliza repercussões na saúde do trabalhador advindas da chegada do processo fabril automotivo.

De acordo com Melo (2015), a fase de instalação de grandes empreendimentos implica uma série de alterações sobre o metabolismo social, com frequente aumento populacional e modificações na dinâmica social que podem resultar em aumento da violência, do consumo de drogas, da exploração sexual de mulheres e adolescentes e, muitas vezes, em processos de desterritorialização dessas populações.

Na dimensão da violência social, temos como destaque o aumento alarmante dos casos de violência doméstica, sexual ou outras violências. De acordo com o Sistema de Informação de Agravos de Notificação (Sinan) (Brasil, 2017), as notificações de casos de violência doméstica, sexual e ou outras violências passaram de 16, em 2012, para 105 em 2013 (início da instalação do polo automotivo), com variação da taxa de morbidade de 0,21 para 1,35, ou seja, crescimento de $543 \%$.

As mulheres atingidas pelos grandes empreendimentos sofrem as consequências desses projetos em suas vidas, com destaque para o não reconhecimento do trabalho doméstico e do campo; a não qualificação das mulheres do campo para o trabalho urbano; a forma autoritária com que os funcionários das empresas tratam e discriminam as mulheres; a perda dos vínculos com a comunidade e a quebra dos laços familiares; e o agravamento da violência sexual e a prostituição. Há, pois, a apropriação individual, por meio da violência doméstica e do trabalho doméstico, e a apropriação coletiva, através do assédio e da exploração sexual (Barroso, 2017).

Desse modo, diante de todos os indicadores sistematizados em relação a força motriz, pressões, situação, exposições e efeitos do framework, conseguimos retratar as mudanças no território de Goiana possivelmente relacionadas à chegada do empreendimento automotivo, evidenciando as relações de processos produtivos, mudanças nas dinâmicas do trabalho, modificações na situação da reprodução social local, em diferentes níveis de complexidade, com apreensão dos efeitos à saúde humana e ambiental gerados por processos de vulnerabilização socioambientais.

\section{Ações}

A análise do framework possibilita um olhar mais detalhado sobre a situação atual do território de Goiana. Assim, para cada nível identificado no modelo, propôs-se, no Quadro 2, um conjunto de ações para a prevenção e a mitigação dos danos associados às pressões sobre o ambiente e a saúde humana. 


\section{Destacam-se os indicadores para exposição e efeito como possíveis de serem} utilizados pela vigilância em saúde ambiental e em saúde do trabalhador.

\section{Quadro 2}

Ações e indicadores para monitoramento das mudanças territoriais relacionadas à matriz força motriz, pressões, situação, exposições e efeitos (FPSEEA) - complexo automotivo multinacional, Goiana, Pernambuco, Brasil

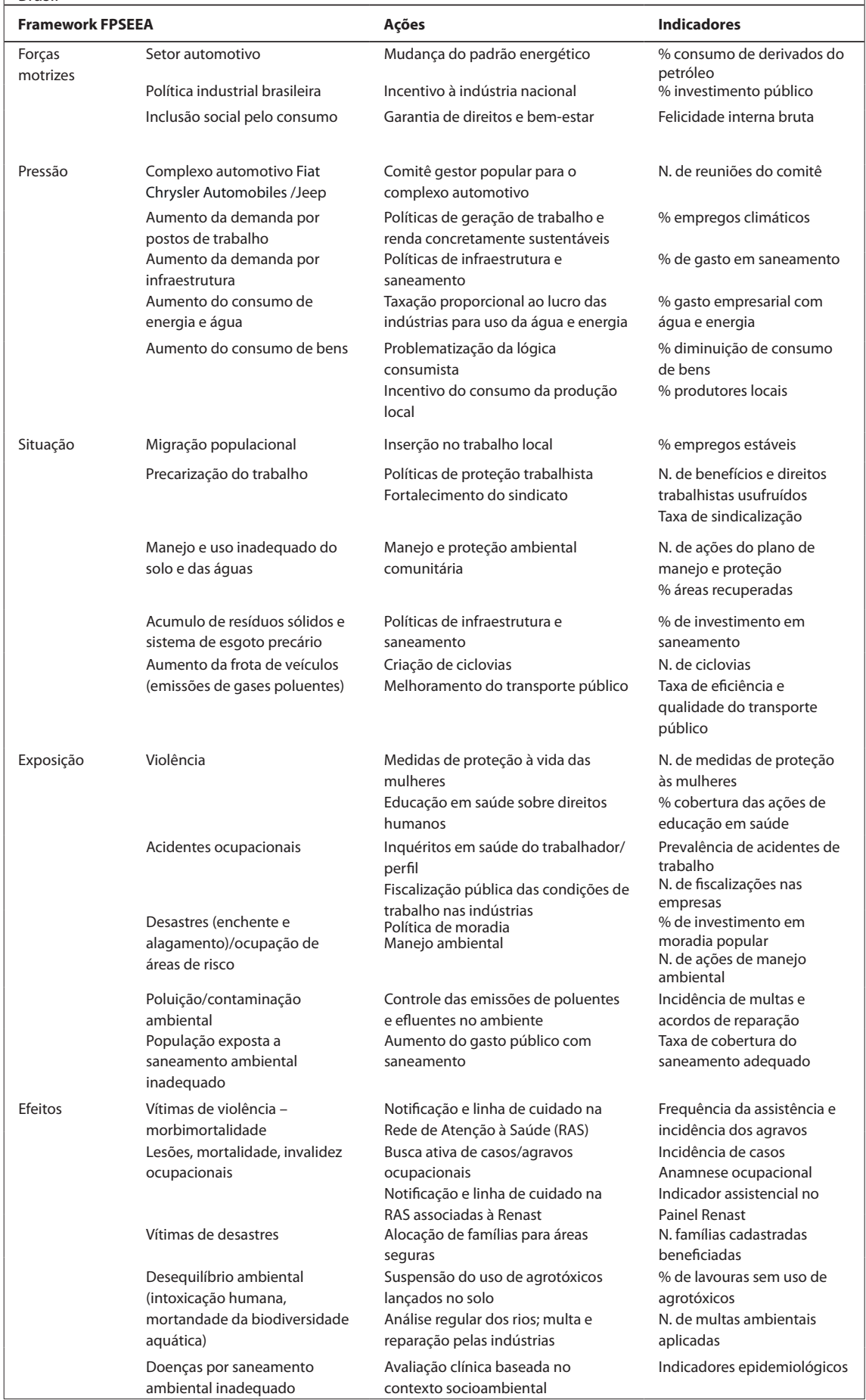

Fonte: Elaboração dos autores, 2018. 
Desse modo, ressalta-se a aplicabilidade do framework FPSEEA na vigilância em saúde ao serem apontadas ações em curto, médio e longo prazos. As ações nos níveis de força motriz (FM) e pressão (P) sugerem ser mais eficazes em relação às ações sobre efeitos gerados pelas mais diversas situações (S), uma vez que são capazes de fazer diminuir ou cessar o desencadeamento dos níveis posteriores (Araujo-Pinto et al., 2012). Observa-se que as ações voltadas à vigilância em saúde e ao controle de exposições (Ex) relacionadas à violência, a acidentes de trabalho, à contaminação ambiental, ao manejo inadequado do solo e do saneamento podem antecipar-se aos efeitos (E), agravos e vítimas na vida singular e nos sistemas socioecológicos.

Assim, ao compreendermos o desencadeamento das dimensões que geram processos de vulnerabilização em saúde, observamos a necessidade da articulação das relações de produção, trabalho, ambiente e saúde para a análise e o monitoramento das mudanças no território.

\section{Considerações finais}

Conclui-se que as contribuições do framework FPSEEA possibilitam o estabelecimento de conexões entre a saúde humana, processos produtivos, dinâmicas de trabalho e o meio ambiente, oferecendo uma plataforma para que os constituintes no campo da saúde e da natureza sejam articulados a fim de que, mediante a compreensão ampliada do processo saúde e doença, sejam estruturadas modificações nos contextos locais.

Nesse sentido, a vulnerabilização é um conceito relevante para compreendermos a imposição de práticas espaciais e agravamentos ao bem viver local, à natureza, às relações sociais e à vida humana singular e comunitária - porque prioriza a compreensão dos processos pelos quais a ação do capital, por meio de empresas e do Estado, busca obter facilidades para seus ciclos de acumulação em detrimento dos grupos sociais historicamente destituídos e dos sistemas socioecológicos.

No cenário da limitada eficácia do Estado em lidar com tais questões de saúde, muitos desses problemas não são sequer identificados, como possivelmente relacionados aos processos produtivos e de trabalho ou às transformações territoriais engendradas pela chegada de grandes empreendimentos. Essas limitações podem ser superadas pela atuação institucional efetiva da vigilância de agravos à saúde e ao ambiente, assim como pela formação de profissionais de saúde comprometidos na intervenção no processo saúde-trabalho-ambiente. 


\section{Colaboradores}

Isabelle Maria Mendes de Araujo realizou o projeto da pesquisa, executou a coleta de dados, análise e sistematização dos resultados e elaborou o texto final. Angelo Giuseppe Roncalli da Costa Oliveira revisou o texto e colaborou na organização do artigo.

Não houve financiamento.

\section{RELACIONES DE PRODUCCIÓN, TRABAJO, AMBIENTE Y SALUD EN UN COMPLEJO AUTOMOTRIZ MULTINACIONAL EN PERNAMBUCO, BRASIL}

Resumen El estudio que originó este artículo, realizado entre el 2015 y el 2017, busca la comprensión de posibles relaciones en el ámbito productivo, ambiental y sanitario en la ciudad de Goiana, Pernambuco, ante la llegada del emprendimiento multinacional de Fiat Chrysler Automóviles. El objetivo es construir una matriz explicativa con base en el framework fuerza motrizpresión-situación-exposición-efecto-acción con sistematización de indicadores para el monitoreo de cambios en el territorio que puedan afectar la salud de la población local y el ambiente por causa de la instalación del complejo automotriz. Para tal, fueron propuestos componentes descriptivos para cada dimensión de la matriz y realizada sistematización de datos secundarios en diferentes bancos de datos. Hubo aprehensión de efectos al bien vivir en el contexto local resultantes de la exposición territorial al aumento de la violencia, precarización y agravios relacionados al trabajo, contaminación ambiental y saneamiento básico precario. Son propuestas acciones para el enfrentamiento de problemas complejos y sistémicos identificados, las cuales pueden subsidiar estrategias para la vigilancia en salud ambiental y en salud del trabajador. Por medio del framework, podemos trazar procesos de vulnerabilización en el territorio local asociándolos a fuerzas estructurantes productivas y las modificaciones en la situación de la reproducción social.

Palabras clave vulnerabilidad; vigilancia en salud ambiental; salud del trabajador. 


\section{Referências}

AGÊNCIA ESTADUAL DE MEIO AMBIENTE DE PERNAMBUCO (CPRH). Diagnóstico socioambiental dos recursos hídricos: monitoramento da Bacia do Rio Goiana. Recife: CPRH, 2017.

AGÊNCIA ESTADUAL DE PLANEJAMENTO E PESQUISAS DE PERNAMBUCO (CONDEPE/FIDEM). Norte Metropolitano e Goiana: oportunidades e desafios para o desenvolvimento regional sustentável. Recife: Condepe, 2010.

ALOCHIO, Ana C. Análise das internações por causas externas no Estado do Espírito Santo. 2011. 238 f. Dissertação (Mestrado em Saúde Coletiva) - Programa de Pós-Graduação em Atenção à Saúde Coletiva da Universidade Federal do Espírito Santo UFES, 2011.

ALVES, Laís S.; WILBERT, Marcelo D. Redução do Imposto sobre Produto Industrializado e a Venda de Automóveis. In: CONGRESSO USP INICIAÇÃO CIENTÍFICA, 11., São Paulo, 21 a 23 de Julho, 2014. Disponível em: < https://congressousp.fipecafi.org/anais/artigos142014/265. pdf>. Acesso em: 27 ago. 2017.

ARAÚJO, Isabelle et al. Recursos hídricos e saúde humana: impactos industriais e estratégias de manejo e proteção ambiental no município de Goiana/PE. INTERthesis, Florianópolis, v. 13, n. 3, p. 163-181, 2016.

ARAUJO, Isabelle; OLIVEIRA, Angelo. Agronegócio e agrotóxicos: impactos à saúde dos trabalhadores agrícolas no Nordeste brasileiro. Trabalho, Educação e Saúde, Rio de Janeiro, v. 15, n. 1, p. 117-129, 2017.

ARAUJO-PINTO, Mariana et al. Utilização do modelo FPEEEA (OMS) para a análise dos riscos relacionados ao uso de agrotóxicos em atividades agrícolas do estado do Rio de Janeiro. Ciência \& Saúde Coletiva, Rio de Janeiro, v. 17, n. 6, p. 1.543-1.555, 2012.
BANCO DE DADOS DO ESTADO DE PERNAMBUCO (BDE-PE). Disponível em: < http:// www.bde.pe.gov.br>. Acesso em: 20 ago. 2017.

BARROSO, Milena. Violência contra mulheres em grandes projetos na Amazônia: mercadorização da vida no capitalismo. Argumentum, Vitória, v. 9, n. 1, p. 89-102, jan.-abr. 2017.

BRASIL. Ministério da Saúde. Secretaria de Vigilância em Saúde. Saúde ambiental: guia básico para construção de indicadores. Brasília: Ministério da Saúde, 2011.

BRASIL. Ministério da Saúde. Departamento de Informática do Sistema Único de Saúde (Datasus). Banco de dados do Sistema Único de Saúde-Datasus. Disponível em: <http:// www.datasus.gov.br>. Acesso em: set. 2017.

BREILH, Jaime. De la vigilancia convencional al monitoreo participativo. Ciência \& Saúde Coletiva, Rio de Janeiro, v. 8, n. 4, p. $937-$ 951, 2003.

BREILH, Jaime. Epidemiología del siglo XXI y ciberespacio: repensar la teoria del poder y la determinación social de la salud. Revista Brasileira de Epidemiologia, São Paulo, v. 18, n. 4, p. 972-982, 2015.

CARDOSO, André et al. O setor automotivo no Brasil: emprego, relações de trabalho e estratégias sindicais. São Paulo: Análise Editorial, n. 14, p. 4-18, 2015.

CARNEIRO, Fernando. Meeting report: development of environmental health indicators in Brazil and other countries in the Americas. Environmental Health Perspectives, North Carolina, v. 114, n. 9, p. 1.407-1.408, 2006.

CORONEL, Daniel; AZEVEDO, André. Política industrial e desenvolvimento econômico: a reatualização de um debate histórico. Revista de Economia Política, São Paulo, v. 34, n. 1, p. 103-119, mar. 2014. 
FRANCO, Angela. Em tempos globais, um 'novo' local: a Ford na Bahia. Caderno $C R H$, Salvador, v. 22, n. 56, p. 59-71, maio-ago. 2009.

FREITAS, Carlos M. et al. Conquistas, limites e obstáculos à redução de riscos ambientais à saúde nos 30 anos do Sistema Único de Saúde. Ciência \& Saúde Coletiva, Rio de Janeiro, v. 23, n. 6, p. 1.981-1.996, 2018.

GENTRY-SHIELDS, Jennifer; BARTRAM, Jamie. Human health and the water environment: using the DPSEEA framework to identify the driving forces of disease. Science of the Total Environment, Amsterdã, v. 306, n. 14, p. 468-469, 2014.

HAMBLING, Tammy et al. A review of frameworks for developing environmental health indicators for climate change and health. International Journal of Environmental Research and Public Health, Basel, v. 88, p. 1-22, 2011.

\section{INSTITUTO BRASILEIRO DE GEOGRAFIA E} ESTÍSTICA (IBGE). População estimada. Disponível em: <https://cidades.ibge.gov.br/brasil/ pe/goiana/panorama>. Acesso: ago. 2017.

LADOSKY, Mario. Tradição e modernização das relações de classe em Goiana (PE). In: ENCONTRO DA ASSOCIAÇÃO NACIONAL DE PÓS-GRADUAÇÃO E PESQUISA EM CIÊNCIAS SOCIAIS (ANPOCS), 39, Caxambu, 2015. Disponível em: <https://anpocs.com/index. php/encontros/papers/39-encontro-anual-daanpocs/gt/gt4l/9835-tradicao-e-modernizacaodas-relacoes-de-classe-em-goiana-pe/file $>$. Acesso em: 18 set. 2018.

LIU, Hai et al. Approaches to integrated monitoring for environmental health impact assessment. Environmental Health, North Carolina, v. 11, p. 88,2012 .

MELO, Rafael. Riscos ambientais, processos de vulnerabilização e controvérsias em torno do Projeto de Mineração de Urânio e Fosfato em Santa Quitéria, Ceará. 2015. 154 f. Dissertação
(Mestrado) - Programa de Pós-Graduação em Desenvolvimento e Meio Ambiente, Universidade Federal do Ceará, Fortaleza, 2015.

MINAYO, Maria C. S. (org.). Avaliação por triangulação de métodos: abordagem de programas sociais. Rio de Janeiro: Editora Fiocruz, 2010.

POCHMAN, Márcio. Políticas públicas e situação social na primeira década do século XXI. In: SADER, Emir (org.). 10 anos de governos pós-neoliberais no Brasil: Lula e Dilma. São Paulo: Boitempo; Rio de Janeiro: Flacso, 2013. p. 76-82.

PORTO, Marcelo. Complexidade, processos de vulnerabilização e justiça ambiental: um ensaio de epistemologia política. Revista Crítica de Ciências Sociais, Coimbra, v. 93, p. 46-59, 2011.

PORTO, Marcelo et al. Saúde coletiva, território e conflitos ambientais: bases para um enfoque socioambiental crítico. Ciência \& Saúde Coletiva, Rio de Janeiro, v. 19, n. 10, p. 4.071-4.080, 2014.

PORTO, Marcelo et al. Saúde e ambiente na favela: reflexões para uma promoção emancipatória da saúde. Serviço Social \& Sociedade, São Paulo, n. 123, p. 523-543, 2015.

REDE NACIONAL DE ATENÇÃO INTEGRAL À SAÚDE DO TRABALHADOR (RENAST). Painel de informações da Renast. Disponível em: <http://renastonline.ensp.fiocruz.br/>. Acesso em: maio 2017.

RIGOTTO, Raquel et al. Desvelando as tramas entre saúde, trabalho e ambiente nos conflitos ambientais: aportes epistemológicos, teóricos e metodológicos. In: RIGOTTO, Raquel. Tramas para a justiça ambiental: diálogo de saberes e práxis emancipatórias. Fortaleza: Edições UFC, 2018. p. 125.

SISTEMA NACIONAL DE INFORMAÇÕES SOBRE SANEAMENTO (SNIS). Diagnóstico 
do manejo de resíduos sólidos urbanos 2015. Brasília: Ministério das Cidades/Sistema Nacional de Saneamento Ambiental, 2017.

TAMBELLINI, Ana. Desenvolvimento, trabalho, saúde e meio ambiente. Rio de Janeiro: Cebes, 2012.
TRIBUNAL REGIONAL FEDERAL DA $5^{\mathrm{a}}$ REGIÃO (TRF5). Agravo de instrumento PE: Processo n. 0804995-22.2015.4.05.0000. Relator: Desembargador Federal Paulo Roberto de Oliveira Lima. 2015. Disponível em: <http:// www.trf5.jus.br/data/2015/10/PJE/0804995 2220154050000_20151021_64051_40500003 219135.pdf >. Acesso em: abr. 2017. 